\title{
Magnitude of Anemia in Geriatric Population Visiting Outpatient Department at the University of Gondar Referral Hospital, Northwest Ethiopia: Implication for Community-Based Screening
}

\author{
Mulugeta Melku (D), ${ }^{1}$ Wondimu Asefa, ${ }^{2}$ Ahmed Mohamednur, ${ }^{2}$ Tesfahun Getachew, ${ }^{2}$ \\ Bayechish Bazezew, ${ }^{2}$ Meseret Workineh $\left(\mathbb{D},{ }^{3}\right.$ Bamlaku Enawgaw ${ }^{D},{ }^{1}$ Belete Biadgo $\left(\mathbb{D},{ }^{4}\right.$ \\ Zegeye Getaneh, ${ }^{1}$ Debasu Damtie $\left(\mathbb{D},{ }^{3}\right.$ and Betelihem Terefe ${ }^{1 D}{ }^{1}$ \\ ${ }^{1}$ Department of Hematology and Immunohematology, School of Biomedical and Laboratory Sciences, \\ College of Medicine and Health Sciences, University of Gondar, 6200 Gondar, Ethiopia \\ ${ }^{2}$ Department of Medical Laboratory Sciences, School of Biomedical and Laboratory Sciences, \\ College of Medicine and Health Sciences, University of Gondar, Gondar, Ethiopia \\ ${ }^{3}$ Department of Immunology and Molecular Biology, School of Biomedical and Laboratory Sciences, \\ College of Medicine and Health Sciences, University of Gondar, Gondar, Ethiopia \\ ${ }^{4}$ Department of Clinical Chemistry, School of Biomedical and Laboratory Sciences, College of Medicine and Health Sciences, \\ University of Gondar, Gondar, Ethiopia \\ Correspondence should be addressed to Mulugeta Melku; mulugeta.melku@gmail.com
}

Received 26 July 2017; Accepted 16 December 2017; Published 8 January 2018

Academic Editor: Fulvio Lauretani

Copyright (C) 2018 Mulugeta Melku et al. This is an open access article distributed under the Creative Commons Attribution License, which permits unrestricted use, distribution, and reproduction in any medium, provided the original work is properly cited.

\begin{abstract}
Objective. This study is aimed at assessing the magnitude and its associated factors of anemia in geriatric population visiting outpatient department at the University of Gondar referral hospital, northwest Ethiopia. Method. A cross-sectional study was conducted among elder patients in Gondar town, North Gondar District, in May 2013. A total of 200 randomly selected geriatric population participated in the study. Summary statistics were computed and presented in tables and figure. Both bivariate and multivariable binary logistic regression were fitted to identify associated factors. A $P$ value $<0.05$ was considered as statistically significant. Result. The median age of the study participants was 65 years (Interquartile range (IQR): 8 years). The prevalence of anemia in the geriatric patients was $54.5 \%(n=109)$, of which $61.5 \%(n=67)$ were males. Mild type anemia was predominant, $55.96 \%(n=61)$. Geriatric patients with an elevated erythrocyte sedimentation rate (AOR = 9.04, 95\% CI: 4.2-19.7) and who are vegetarians $(\mathrm{AOR}=2.2,95 \% \mathrm{CI}: 1.03-4.71)$ were at high risk of developing anemia. Conclusion. The magnitude of anemia was high in geriatrics. Mild anemia was the predominant type. Vegetarians and geriatrics with elevated erythrocyte sedimentation rate were more likely to develop anemia. Hence, early diagnosis and management of anemia have paramount importance to prevent adverse outcomes in geriatrics.
\end{abstract}

\section{Background}

Anemia is a decrease in the number of red blood cells or hemoglobin $(\mathrm{Hb})$, resulting in a lower ability for the blood to carry oxygen to body tissues. As to World Health Organization (WHO) recommendation, anemia as $\mathrm{Hb}$ level < $12.0 \mathrm{~g} / \mathrm{dL}$ for women and $<13.0 \mathrm{~g} / \mathrm{L}$ for men is most frequently used, even though the appropriateness in older populations may be questioned [1]. Anemia is a worldwide public health problem, with global prevalence estimated to be $24.8 \%$ (95\% CI: 22.9-26.7). The majority of the global disease burden of anemia is shouldered by the developing world, with high prevalence in Africa and southeast Asia [2].

In geriatric age group, anemia is a common concern and public health problem [3-6]. It is frequently underdiagnosed and often not reported to the patient because it is mostly 
perceived as a mere consequence of aging or as a disease marker [7]. However, anemia has been implicated with severe complications. It can greatly hamper the quality of life and, consequently, it can have an impact on healthcare requirements and expenditure. Thus, it is becoming a significant healthcare burden $[8,9]$.

Evidences showed that anemia in elderly has been strongly linked with severe complications, including impaired physical functioning [10], decreased functionality [11], multidimensional loss of function [12], increased risk of frailty [1315], depression [16], cognitive impairment [17], obstructive sleeping apnea [18], frequent comorbidity and hospitalization [19-21], and increased risk of death [20, 22, 23]. Despite old age being a major risk factor for anemia which threatens the quality of elderly life and has a substantial social and economic effects, anemia, however, should not be accepted as an inevitable consequence of aging, as it does reflect poor health and increased vulnerability to adverse outcomes in older persons [24, 25].

Anemia in elderly is multifactorial in etiology and a complex interaction of many factors. Causes of anemia in the elderly are divided into three groups: anemia of chronic disease, nutritional deficiency, and unexplained anemia [26]. These groups are not, however, mutually exclusive. In most of the cases, several of these causes may coexist and may each contribute independently to the anemia. The most common causes of anemia in the elderly are chronic diseases and iron deficiency [24]. Approximately, one-third of anemia in elderly person has attributed to nutrient deficiency; most of these cases are attributable to iron deficiency, including chronic blood loss. Moreover, folate deficiency and vitamin B12 deficiency are also causes of nutritional anemia and warrant routine screening. Although fortification of foodstuffs has made folate deficiency less common, more than $10 \%$ of elderly persons have borderline or low vitamin B12 levels $[25,27]$.

Although numerous studies on the prevalence of anemia in the elderly have been published, they vary markedly in study design and populations sampled and, consequently, in its prevalence range widely $[3,15,21,28,29]$. Despite the increasing size of the geriatric population in Ethiopia, much has not been done to determine the epidemiology of anemia in this group of the population.

\section{Methods and Materials}

2.1. Study Design, Period, Setting, Population, and Sampling Techniques. This institution based cross-sectional study was conducted in the outpatient department of University of Gondar Hospital in May 2013. The sample size was estimated by using single population proportion at $95 \%$ confidence interval, sampling error of $5 \%$, and an estimated anemia prevalence of $50 \%$ in the elderly population. The sample size was corrected into 200, as the estimated number of elderly patients visiting the hospital during the study period was lower than 10,000. A systematic random sampling was applied; participants were selected at every second interval from the sequence of outpatient department visit.
On the basis of the proposed working definition of an "older person" in Africa for the Minimum Data Set (MDS) project [30], elderly patients with the age of 60 years and above for both men and women and who had not been transfused with red blood cells within the previous three months were included. Those elderly patients who were seriously ill and unable to respond to the questions during the time of data collection were excluded from the study for ethical reasons.

2.2. Data Collection Method. Sociodemographic and clinical history of the study participants were collected by using pretested structured questionnaire via interview and medical record review, respectively. Height and weight of each study participants were measured using standard scales as recommended by WHO. BMI was computed as weight $(\mathrm{kg}) /$ height $\left(\mathrm{m}^{2}\right)$. Based on BMI, nutritional status was evaluated and grouped as follows: underweight $(\mathrm{BMI} \leq 18.5)$, normal weight $(\mathrm{BMI}=18.5-24.9)$, and overweight $(\mathrm{BMI} \geq 25.0)$.

2.3. Laboratory Methods and Assessment of Anemia. Three milliliters of venous blood was drawn into $\mathrm{K}_{3}$ EDTA tube and analyzed for complete blood count (CBC) and erythrocyte sedimentation rate (ESR). The CBC was determined using a Sysmex KX-21N (Sysmex Corporation Kobe, Japan) automated hematology analyzer. Anemia was defined according to the WHO criteria as an adjusted $\mathrm{Hb}$ concentration lower than $12.0 \mathrm{~g} / \mathrm{dL}$ for women and $13.0 \mathrm{~g} / \mathrm{dL}$ for men. Severity of anemia was graded as severe $(\mathrm{Hb}<8.0 \mathrm{~g} / \mathrm{dL})$ and moderate (Hb: $8.0-10.9 \mathrm{~g} / \mathrm{dL}$ ) for both men and women and as mild (Hb: 11.0-12.9 g/dL for men and Hb: 11.0-11.9 g/dL for women) [1]. Morphological classification of anemia was done by using red cell indices, and the reference values used in this study were MCV (80-100 fl), MCHC (31-35\%), and $\mathrm{MCH}$ (27-32 pg). We used IRIA (LiNEAR Chemicals, SL, Spain) for determination of ESR and a cutoff value of $20 \mathrm{~mm} / \mathrm{hr}$ and $30 \mathrm{~mm} / \mathrm{hr}$ was used for men and women, respectively.

2.4. Data Analysis and Interpretation. Data were entered to EPI info version 3.5.3 and then transferred to SPSS version 20 statistical package for analysis. Summary statistics were computed, and the results were presented in tables and figure. A binary logistic regression model was fitted to identify factors associated with anemia. Odds ratio, Chi-square, and 95\% CI for odds ratio were computed to assess the strength of association and statistical significance in bivariate analysis. Variables having $P$ less than or equal to 0.2 in bivariate binary logistic regression analysis were included in multivariable binary logistic regression analysis to control confounders. A $P$ value less than 0.05 in the multivariable binary logistic regression model was considered to be statistically significant.

2.5. Ethical Consideration. The study was approved by an Institutional Review Board of the University of Gondar. The purpose and importance of the study were explained to each study participants. Written consent was obtained from each participant. To ensure confidentiality of participants' information, anonymous typing was used whereby the name of the participants and any participants' identifier were 
not written on the questionnaire. To keep the participants' privacy, they were interviewed alone in a separate room.

\section{Results}

3.1. Characteristics of Study Participants. Two hundred $(n=$ 200 ) elderly patients participated in this study. The median age of the study participants was 65 years (IQR: 8 years). About one-third, $(35 \%, n=70)$, of them, belong to $60-64$ years age group. Majority of the elderly patients were males (55\%, $n=110)$, and most of the study participants reside in an urban setting $(55.5 \%, n=111)$. More than three-fourths (77\%, $n=154)$, half $(61 \%, n=122)$, and one-third $(43 \%$, $n=86)$ of the participants were married, unable to read and write, and farmer by occupation, respectively. The average monthly family income of the study participants was 1093.36 Ethiopia Birr (ETB), of which $42 \%(n=84)$ had an income of less than 1000 ETB. The proportion of elderly patients with a family size of greater than 6 accounts for $15.5 \%(n=31)$ (Table 1).

3.2. Dietary Habit and ESR Value of Study Participants. About $78 \%(n=156)$ and $69.5 \%(n=139)$ of the study participants had a habit of consuming fruits less frequently and meat at least once a week, respectively. Moreover, $62 \%(n=124)$ of them had a habit of taking coffee and/or tea after a meal, whereas $44.5 \%(n=89)$ of them had a habit of consuming vegetables less frequently. Concerning the nutritional status and ESR status of the study participants, $26 \%(n=52)$ and $70.5 \%(n=141)$ of them were underweighted and had an elevated ESR value, respectively (Table 2).

3.3. Anemia Prevalence and Its Severity. The median (IQR) $\mathrm{Hb}$ concentration for males and females was $12.5 \mathrm{~g} / \mathrm{dl}$ (IQR: $2.6 \mathrm{~g} / \mathrm{dl}$ ) and $12.15 \mathrm{~g} / \mathrm{dl}$ (IQR: $2.85 \mathrm{~g} / \mathrm{dl}$ ), respectively. The prevalence of anemia in the elderly patients was $54.5 \%$ (95\% CI: 47.54-61.46). Out of the total anemic elderly patients, 7 (6.4\%), 40 (36.7\%), and 62 (56.9\%) had severe, moderate, and mild anemia, respectively (Table 3 ). Regarding morphologic feature of anemia, the majority of anemic patients had been suffering from normocytic normochromic anemia, 85.3\% $(n=93)$ (Figure 1$)$.

3.4. Factors Associated with Elderly Anemia. In bivariate binary logistic regression analysis, male sex, vegetarians, elevated ESR, underweight, and normal weight were significantly associated with elderly anemia. But in multivariable binary logistic regression analysis controlling the possible cofounders, only vegetarians and elevated ESR value were found to be factors statistically associated with elderly anemia. The odds of anemia in elderly patients who were vegetarians were two times ( $\mathrm{AOR}=2.2,95 \% \mathrm{CI}$ : 1.03-4.71) higher than the odds of anemia in elderly patients who had a habit of consuming meat at least once in every two weeks. Similarly, elderly patients who had an elevated ESR were nine times ( $\mathrm{AOR}=9.04,95 \% \mathrm{CI}: 4.2-19.7)$ more likely to be anemic as compared to those whose ESR value was within the normal range (Table 4).
TABLE 1: Sociodemographic characteristics of study participants $(n=200)$.

\begin{tabular}{|c|c|c|}
\hline Variables & Frequency & Percent \\
\hline \multicolumn{3}{|l|}{ Age (years) } \\
\hline $60-64$ & 70 & 35 \\
\hline $65-69$ & 54 & 27 \\
\hline $70-74$ & 38 & 19 \\
\hline$>74$ & 38 & 19 \\
\hline \multicolumn{3}{|l|}{ Sex } \\
\hline Female & 90 & 45 \\
\hline Male & 110 & 55 \\
\hline \multicolumn{3}{|l|}{ Residence } \\
\hline Urban & 111 & 55.5 \\
\hline Rural & 89 & 44.5 \\
\hline \multicolumn{3}{|l|}{ Marital status } \\
\hline Single & 1 & 0.5 \\
\hline Married & 154 & 77 \\
\hline Divorced & 15 & 7.5 \\
\hline Widowed & 30 & 15 \\
\hline \multicolumn{3}{|l|}{ Educational level } \\
\hline Unable read and write & 122 & 61 \\
\hline Attended primary school & 32 & 16 \\
\hline Attended secondary school & 27 & 13.5 \\
\hline Attended higher education & 19 & 9.5 \\
\hline \multicolumn{3}{|l|}{ Occupation } \\
\hline Daily laborer & 9 & 4.5 \\
\hline Private employee & 21 & 10.5 \\
\hline Governmental employee & 37 & 18.5 \\
\hline Farmer & 86 & 43 \\
\hline Housewife and retired & 47 & 23.5 \\
\hline \multicolumn{3}{|l|}{ Family size } \\
\hline 1-3 members & 54 & 27 \\
\hline 4-6 members & 115 & 57.5 \\
\hline$>6$ members & 31 & 15.5 \\
\hline \multicolumn{3}{|l|}{ Monthly income (ETB) } \\
\hline$<1000$ & 84 & 42 \\
\hline $100-1500$ & 90 & 45 \\
\hline$>1500$ & 26 & 13 \\
\hline
\end{tabular}

\section{Discussion}

Anemia is a critical clinical problem in the elderly population, especially in hospitalized geriatric patients, and is known to be associated with increased morbidity and mortality. The present institutional based cross-sectional study found that the prevalence of anemia in elderly patients visiting outpatient department was high, and elevated ESR and being vegetarian were found to be strongly associated with geriatric anemia.

In this study, elderly patients had anemia prevalence of $54.5 \%$, and according to WHO cutoff anemia has severe public health significance in this group [1]. It is comparable to the prevalence reported by Sahin et al. (54.9\%) [31]. It is also comparable with a study reported by Tay and Ong (57.1\%) 
TABLE 2: Dietary habit, nutritional status, and ESR value of study participants $(n=200)$.

\begin{tabular}{lcc}
\hline Variables & Frequency & Percentage \\
\hline Meat consumption habit & & \\
Consumed at least once a week and more & 139 & 69.5 \\
Vegetarians & 61 & 30.5 \\
Frequency of fruit consumption & & \\
At least once a week and more & 44 & 22 \\
Less frequently & 156 & 78 \\
Frequency of vegetable consumption & & \\
At least once a week and more & 111 & 55.5 \\
Less frequently & 89 & 44.5 \\
Coffee or tea consumption habit after meal & & \\
Yes & 124 & 62 \\
No & 76 & 38 \\
Nutritional status, BMI & & \\
Underweight & 52 & 26 \\
Normal & 133 & 66.5 \\
Overweight & 15 & 7.5 \\
ESR & & \\
Normal & 59 & 29.5 \\
Elevated & 141 & 70.5 \\
\hline BMI Body
\end{tabular}

BMI: Body mass index; ESR: erythrocyte sedimentation rate.

TABLE 3: Summary of anemia severity among anemic study participants $(n=109)$.

\begin{tabular}{lcc}
\hline Variables & Frequency & Percentage \\
\hline Anemia by severity & 62 & \\
Mild & 40 & 56.9 \\
Moderate & 7 & 36.7 \\
Severe & 109 & 6.4 \\
Total & & 54.5 \\
\hline
\end{tabular}

[21], even though the study design and the criteria to define the population and anemia is different from us, as Tay and Ong study was retrospective in elderly hospitalized patients aged 65 and above year and the anemia was not defined according to WHO criterion. However, it is higher than the prevalence reported by Nakashima et al. (29\%) [3], Sgnaolin et al. (12.8\%) [32], and Bang et al. (8.33\%) [10]. The possible reason for the discrepancies might be the characteristics differences between populations studied. In this study, the study participants were elderly patients who sought medical intervention in outpatients department, whereas in the case of Nakashima et al., Sgnaolin et al., and Bang et al. studies, the participants were institutionalized in long-term care [3] and community-dwelling elderly people [10, 32], who were assumed to be apparently healthy; thereby the risk of anemia is low. Similarly, the prevalence revealed in this study was higher than the prevalence (36.7\%) reported from Reykjavik, Iceland [33], and the prevalence (10.6\%) reported by NHANES III for black Americans [25]. This can be due to the differences in nutritional and environmental factors across the population studied.

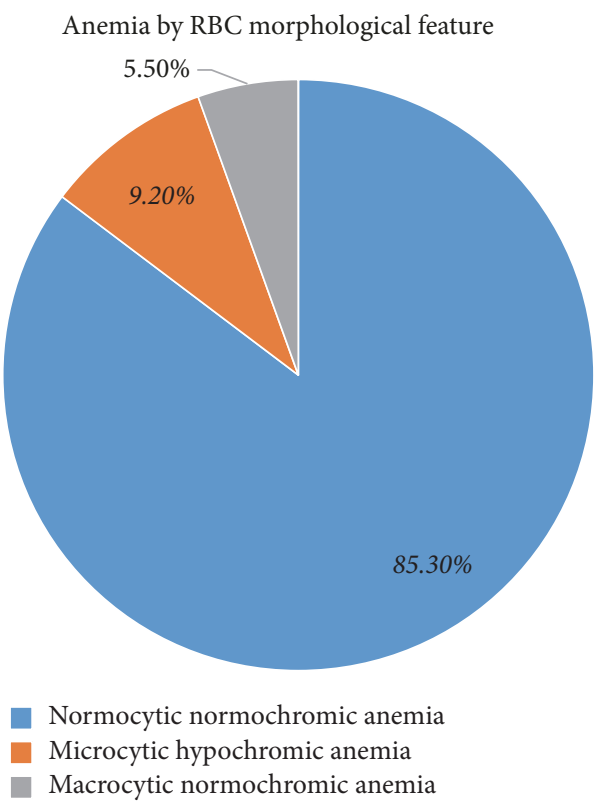

FIGURE 1: RBC morphological feature among anemic elderly study participants $(n=109)$.

On the other hand, the magnitude of anemia in this study was lower than studies carried out by Dunn et al. (77\%) [34] and Kaur et al. (71\%) [29]. This difference can be attributed to the distinctive characteristics of study participants, as Dunn et al. included elderly patients who were admitted to hospital for palliative care and Kaur et al. also included those admitted to in-patients in addition to outpatients; however, in our study only outpatients were considered. In elderly patients admitted to health facilities, the range and degree of comorbid conditions increase the likelihood of anemia development as compared with elderly outpatients. Contingent on these situations, the magnitude of anemia in the present study is lower than those studies conducted among elderly hospitalized patients.

Similar to previous studies carried out by different scholars $[10,21,25,35]$, this study found that the magnitude of anemia was higher in elderly men (60.9\%) than women (46.7\%). Moreover, a systematic review revealed that the estimates of anemia prevalence range from $2.9 \%$ to $61 \%$ in elderly men and from $3.3 \%$ to $41 \%$ in elderly women, but the threshold values are, in general, higher for men than for women [36]. The difference in the prevalence rates of anemia for men and women can be explained by the fact that in each decade beyond the age of 30 , the concentration of free and bioavailable testosterone declines sharply in males. This negatively impacts the enhanced metabolic processes of the bone marrow. As testosterone level decreases with aging, the rate of erythropoiesis tends to be declined and predispose men to increased risk of anemia $[37,38]$. In contrast to elderly men, the postmenopausal estrogen, which acts as an inhibitor of erythropoiesis, declines gradually as women age [39]. This intern would probably decrease the risk of anemia in elderly women as compared to men. 
TABLE 4: Analysis of factors associated with anemia among study participants $(n=200)$.

\begin{tabular}{|c|c|c|c|c|}
\hline \multirow{2}{*}{ Variables } & \multicolumn{2}{|c|}{ Anemia } & \multirow{2}{*}{ COR $(95 \% \mathrm{CI})$} & \multirow{2}{*}{$\operatorname{AOR}(95 \% \mathrm{CI})$} \\
\hline & Anemic (\%) & Non-anemic (\%) & & \\
\hline \multicolumn{5}{|l|}{ Sex } \\
\hline Male & $67(60.9)$ & $43(39.1)$ & $1.78(1.01,3.13)^{\mathrm{b}}$ & $1.53(0.79,2.96)$ \\
\hline Female & $42(46.7)$ & $48(53.3)$ & 1.00 & \\
\hline \multicolumn{5}{|l|}{ Residence } \\
\hline Urban & $56(50.5)$ & $45(49.5)$ & 1.00 & \\
\hline Rural & $53(59.6)$ & $36(40.4)$ & $1.45(0.82,2.54)$ & \\
\hline \multicolumn{5}{|l|}{ Age group (year) } \\
\hline $60-64$ & $33(47.1)$ & $37(52.9)$ & 1.00 & \\
\hline $65-69$ & $35(64.8)$ & $19(35.2)$ & $2.10(0.99,4.30)^{+}$ & \\
\hline $70-74$ & $19(50)$ & $19(50)$ & $1.12(0.51,2.47)$ & \\
\hline$>74$ & $22(57.9)$ & $16(42.1)$ & $1.54(0.70,3.42)$ & \\
\hline \multicolumn{5}{|l|}{ Marital Status } \\
\hline Married & $80(51.9)$ & $74(48.1)$ & 1.00 & \\
\hline Single or divorced & $10(62.5)$ & $6(37.5)$ & $1.54(0.53,4.45)$ & \\
\hline Widowed & $19(63.3)$ & $11(36.7)$ & $1.60(0.71,3.58)$ & \\
\hline \multicolumn{5}{|l|}{ Educational status } \\
\hline Unable read and write & $68(55.7)$ & $54(44.3)$ & $1.14(0.64,2.01)$ & \\
\hline Attended primary school or above & $41(52.6)$ & $37(47.4)$ & 1.00 & \\
\hline \multicolumn{5}{|l|}{ Occupation } \\
\hline Daily laborers, housewives and retired & $28(50)$ & $28(50)$ & $0.76(0.36,1.58)$ & \\
\hline Farmers & $48(55.8)$ & $38(44.2)$ & $0.9(0.5,1.87)$ & \\
\hline Employed (private and government) & $33(56.9)$ & $25(43.1)$ & 1.00 & \\
\hline \multicolumn{5}{|l|}{ Family size } \\
\hline $1-3$ members & $26(48.1)$ & $28(51.9)$ & 1.00 & \\
\hline $4-6$ members & $64(55.7)$ & $51(44.3)$ & $1.35(0.71,2.58)$ & \\
\hline$>6$ members & $19(61.3)$ & $12(38.7)$ & $1.71(0.69,4.2)$ & \\
\hline \multicolumn{5}{|l|}{ Meat consumption habit } \\
\hline Consumed at least once every two weeks and more & $69(49.6)$ & $70(50.4)$ & 1.00 & \\
\hline Vegetarians & $40(65.6)$ & $21(34.4)$ & $1.93(1.04,3.61)$ & $2.2(1.03,4.71)^{*}$ \\
\hline \multicolumn{5}{|l|}{ Frequency of Fruit consumption } \\
\hline At least once a week and more & $23(52.3)$ & $21(47.7)$ & 1.00 & \\
\hline Less frequently & $86(55.1)$ & $70(44.9)$ & $1.12(0.57,2.2)$ & \\
\hline \multicolumn{5}{|l|}{ Frequency of Vegetable consumption } \\
\hline At least once a week and more & $61(55)$ & $50(45)$ & 1.00 & \\
\hline Less frequently & $48(53.9)$ & $41(46.1)$ & $0.96(0.55,1.68)$ & \\
\hline \multicolumn{5}{|l|}{ Coffee or tea consumption habit after meal } \\
\hline Yes & $65(52.4)$ & $59(47.6)$ & $0.8(0.45,1.43)$ & \\
\hline No & $44(57.9)$ & $32(42.1)$ & 1.00 & \\
\hline \multicolumn{5}{|l|}{ Monthly income (ETB) } \\
\hline$<1000$ & $45(53.6)$ & $39(46.4)$ & $0.99(0.41,2.39)$ & \\
\hline $100-1500$ & $50(55.6)$ & $40(44.4)$ & $1.07(0.45,2.57)$ & \\
\hline$>1500$ & $14(53.8)$ & $12(46.2)$ & 1.00 & \\
\hline \multicolumn{5}{|l|}{$E S R$} \\
\hline Normal & $12(20.3)$ & $47(79.7)$ & 1.00 & \\
\hline Elevated & $97(68.8)$ & $44(31.2)$ & $8.63(4.17,17.87)$ & $9.04(4.2,19.7)^{*}$ \\
\hline \multicolumn{5}{|l|}{ Nutritional status, BMI } \\
\hline Underweight & $33(63.5)$ & $19(36.5)$ & $6.95(1.74,27.76)^{\mathrm{b}}$ & $4.02(0.81,19.93)$ \\
\hline Normal & $73(54.9)$ & $60(45.1)$ & $4.87(1.31,18.1)^{\mathrm{b}}$ & $3.61(0.8,16.25)$ \\
\hline Overweight & $3(20 \%)$ & $12(32)$ & 1.00 & \\
\hline
\end{tabular}

ETB: Ethiopian Birr; BMI: body mass index; COR: crude odds ratio; AOR: adjusted odds ratio; and CI: confidence interval. ${ }^{+}$Category of a variable with $P$ value less than 0.2 in bivariate binary logistic regression analysis, ${ }^{\mathrm{b}}$ Category of a variables which were statistically significant in bivariate binary logistic regress but not in multivariable analysis. ${ }^{*}$ Category of a variables which were statistically significant in multivariable binary logistic regression analysis $(P$ value $<0.05)$. 
In this study, the odds of anemia in vegetarians were two times as high as the odds in those who had a habit of consuming meat at least once in every two weeks. Evidence suggested that the omission of meat and other animal products from the diet increases the risk of nutritional deficiencies [40, 41]. As a result, in vegetarians, the risk of vitamin B12, iron, and other several minerals deficiencies is common, which predispose them to an increased risk of nutritional deficiency anemia $[42,43]$. Together with high magnitude of undernutrition which is a major public health concern in many African countries as a consequence of poverty and limitation of access to basic social supports [44] and aging related physiological changes, vegetarians are at higher risk of developing anemia.

In this study, we noticed that elderly patients who had an elevated ESR were nine times $(\mathrm{AOR}=9.04,95 \% \mathrm{CI}$ : 4.2-19.7) more likely to be anemic as compared to those whose ESR value was within the normal range. The systemic inflammation associated with aging as well as chronic/acute conditions has been inferred from commonly used sensitive laboratory tests like ESR and C-reactive protein [45]. It is known that elevated ESR value is strongly correlated with the inflammatory response. Inflammatory conditions result in the accumulation of reactive oxygen species which activate nuclear factor kappa B, a transcription factor playing a central role in activating the innate immune response and inducing the expression of numerous proinflammatory cytokines. These pro-inflammatory cytokines further induce the expression of hepcidin antimicrobial peptide, a critical mediator of anemia of inflammation, which decreases serum iron availability and correlates with serum ferritin [46]. Moreover, patients with inflammatory diseases have been demonstrated to have decreased red cell survival, disorders of erythropoiesis, low erythropoietin response to hypoxia, and progressive erythroid progenitor cell resistance to erythropoietin stimulation [47]. Thus, elderly people having elevated ESR value are at higher risk of developing anemia.

\section{Limitation of the Study}

One of the limitations of this study is that only hemoglobin measurement was used to define anemia; the micronutrient analysis was not done for the assessment of nutritional deficiency anemia. The second limitation is that only ESR was used as an indicator of inflammation; other sensitive indicators like serum C-reactive protein, albumin, and cytokines were not measured. The third limitation of this study is related to the study design and the sample size, as its cross-sectional nature with small sample size.

\section{Conclusion}

In conclusion, the prevalence of anemia was found to be high, indicating that it is a severe public health problem in the study area. Being vegetarians and elevated ESR value have been strongly associated with high prevalence of anemia in elderly outpatients. Hence, provision of community-based anemia screening and nutritional educations are advisable to improve the quality of life and reduce the complications in the elderly population. Moreover, further community-based studies, employing longitudinal design and preferably involving biochemical analysis, are required to identify risk factors as well as to estimate the relative contribution of nutritional status to anemia in this group of the population.

$\begin{array}{ll}\text { Abbreviations } \\ \text { AOR: } & \text { Adjusted odds ratio } \\ \text { BMI: } & \text { Body mass index } \\ \text { CBC: } & \text { Complete blood count } \\ \text { CI: } & \text { Confidence interval } \\ \text { COR: } & \text { Crude odds ratio } \\ \text { ESR: } & \text { Erythrocyte sedimentation rate } \\ \text { ETB: } & \text { Ethiopian Birr } \\ \text { IQR: } & \text { Interquartile range } \\ \text { Hb: } & \text { Hemoglobin } \\ \text { MCH: } & \text { Mean cell hemoglobin } \\ \text { MCHC: } & \text { Mean cell hemoglobin concentration } \\ \text { MCV: } & \text { Mean cell volume } \\ \text { MDS: } & \text { Minimum Data Set } \\ \text { SD: } & \text { Standard deviation } \\ \text { WHO: } & \text { World Health Organization. }\end{array}$

\section{Data Access}

Data will be available upon request from the corresponding author.

\section{Disclosure}

Mulugeta Melku and Betelihem Terefe are co-first authors of the manuscript.

\section{Conflicts of Interest}

The authors declared they have no conflicts of interest regarding the publication this article.

\section{Authors' Contributions}

Mulugeta Melku and Betelihem Terefe equally contributed to this work.

\section{Acknowledgments}

The authors would like to thank the study participants for their volunteer participation. The authors would also like to extend their application for the University of Gondar, School of Biomedical and Laboratory Sciences, and the University of Gondar Referral Hospital for logistic supports.

\section{References}

[1] WHO, Haemoglobin concentrations for the diagnosis of anaemia and assessment of severity. Vitamin and Mineral Nutrition Information System, World Health Organization, Geneva, Switzerland, 2011.

[2] WHO, Worldwide Prevalence of Anaemia 1993-2005, WHO Global Database on Anaemia, Geneva, Switzerland, 2008. 
[3] A. T. A. Nakashima, A. C. F. de Moraes, F. Auler, and R. M. Peralta, "Anemia prevalence and its determinants in Brazilian institutionalized elderly," Nutrition Journal, vol. 28, no. 6, pp. 640-643, 2012.

[4] V. Argento, J. Roylance, B. Skudlarska, N. Dainiak, and Y. Amoateng-Adjepong, "Anemia Prevalence in a Home Visit Geriatric Population," Journal of the American Medical Directors Association, vol. 9, no. 6, pp. 422-426, 2008.

[5] V. Bach, G. Schruckmayer, I. Sam, G. Kemmler, and R. Stauder, "Prevalence and possible causes of anemia in the elderly: A cross-sectional analysis of a large European university hospital cohort," Clinical Interventions in Aging, vol. 9, pp. 1187-1196, 2014.

[6] A. M. van Staden and D. J. V. Weich, "Retrospective analysis of the prevalence and causes of anaemia in hospitalised elderly patients," South African Family Practice, vol. 57, no. 5, pp. 297299, 2015.

[7] M. Tettamanti, U. Lucca, F. Gandini et al., "Prevalence, incidence and types of mild anemia in the elderly: the 'Health and Anemia'population-based study," Haematologica, vol. 95, no. 11, pp. 1849-1856, 2010.

[8] B. Robinson, "Cost of anemia in the elderly," Journal of the American Geriatrics Society, vol. 15, no. 3, pp. s14-s17, 2003.

[9] W. B. Ershler, K. Chen, E. B. Reyes, and R. Dubois, "Economic burden of patients with anemia in selected diseases," Value in Health, vol. 8, no. 6, pp. 629-638, 2005.

[10] S.-M. Bang, J.-O. Lee, Y. J. Kim et al., "Anemia and activities of daily living in the Korean urban elderly population: Results from the Korean Longitudinal Study on Health and Aging (KLoSHA)," Annals of Hematology, vol. 92, no. 1, pp. 59-65, 2013.

[11] R. D. M. Bosco, E. P. S. Assis, R. R. Pinheiro, L. C. V. de Queiroz, L. S. M. Pereira, and C. M. F. Antunes, "Anemia and functional capacity in elderly Brazilian hospitalized patients," Cadernos de Saúde Pública, vol. 29, no. 7, pp. 1322-1332, 2013.

[12] J. Zilinski, R. Zillmann, I. Becker, T. Benzing, R.-J. Schulz, and G. Roehrig, "Prevalence of anemia among elderly inpatients and its association with multidimensional loss of function," Annals of Hematology, vol. 93, no. 10, pp. 1645-1654, 2014.

[13] G. Röhrig, "Anemia in the frail, elderly patient," Clinical Interventions in Aging, vol. 11, pp. 319-326, 2016.

[14] L. Pires Corona, F. C. Drumond Andrade, Y. A. de Oliveira Duarte, and M. L. Lebrao, "The relationship between anemia, hemoglobin concentration and frailty in Brazilian older adults," The Journal of Nutrition, Health \& Aging, vol. 19, no. 9, pp. 935940, 2015.

[15] T. Juárez-Cedillo, L. Basurto-Acevedo, S. Vega-García et al., "Prevalence of anemia and its impact on the state of frailty in elderly people living in the community: SADEM study," Annals of Hematology, vol. 93, no. 12, pp. 2057-2062, 2014.

[16] C. Trevisan, N. Veronese, F. Bolzetta et al., "Low hemoglobin levels and risk of developing depression in the elderly: Results from the prospective PRO.V.A. study," Journal of Clinical Psychiatry, vol. 77, no. 12, pp. e1549-e1556, 2016.

[17] C. Trevisan, N. Veronese, F. Bolzetta et al., "Low Hemoglobin Levels and the Onset of Cognitive Impairment in Older People: The PRO.V.A. Study," Rejuvenation Research, vol. 19, no. 6, pp. 447-455, 2016.

[18] A. M. Khan, S. Ashizawa, V. Hlebowicz, and D. W. Appel, "Anemia of aging and obstructive sleep apnea," Sleep and Breathing, vol. 15, no. 1, pp. 29-34, 2011.
[19] M. Migone De Amicis, E. Poggiali, I. Motta et al., "Anemia in elderly hospitalized patients: prevalence and clinical impact," Internal and Emergency Medicine, vol. 10, no. 5, pp. 581-586, 2015.

[20] B. F. Culleton, B. J. Manns, J. Zhang, M. Tonelli, S. Klarenbach, and B. R. Hemmelgarn, "Impact of anemia on hospitalization and mortality in older adults," Blood, vol. 107, no. 10, pp. 38413846, 2006.

[21] M. R. J. Tay and Y. Y. Ong, "Prevalence and risk factors of anaemia in older hospitalised patients," Proceedings of Singapore Healthcare, vol. 20, no. 2, pp. 71-79, 2011.

[22] F. Landi, A. Russo, P. Danese et al., "Anemia status, hemoglobin concentration, and mortality in nursing home older residents," Journal of the American Medical Directors Association, vol. 8, no. 5, pp. 322-327, 2007.

[23] H. G. Endres, U. Wedding, D. Pittrow, U. Thiem, H. J. Trampisch, and C. Diehm, "Prevalence of anemia in elderly patients in primary care: Impact on 5-year mortality risk and differences between men and women," Current Medical Research and Opinion, vol. 25, no. 5, pp. 1143-1158, 2009.

[24] D. L. Smith, "Anemia in the elderly," American Family Physician, vol. 62, no. 7, pp. 1565-1572, 2000.

[25] J. M. Guralnik, R. S. Eisenstaedt, L. Ferrucci, H. G. Klein, and R. C. Woodman, "Prevalence of anemia in persons 65 years and older in the United States: evidence for a high rate of unexplained anemia," Blood, vol. 104, no. 8, pp. 2263-2268, 2004.

[26] E. Andrès, L. Federici, K. Serraj, and G. Kaltenbach, "Update of nutrient-deficiency anemia in elderly patients," European Journal of Internal Medicine, vol. 19, no. 7, pp. 488-493, 2008.

[27] S. Loikas, P. Koskinen, K. Irjala et al., "Vitamin B12 deficiency in the aged: A Population-Based Study," Age and Ageing, vol. 36, no. 2, pp. 177-183, 2007.

[28] M. López-Sierra, S. Calderón, J. Gómez, and L. Pilleux, "Prevalence of anaemia and evaluation of transferrin receptor (sTfR) in the diagnosis of iron deficiency in the hospitalized elderly patients: Anaemia clinical studies in Chile," Anemia, vol. 2012, Article ID 646201, 2012.

[29] H. Kaur, S. Piplani, M. Madan, M. Paul, and S. G. Rao, "Prevalence of Anemia and Micronutrient Deficiency in Elderly," International Journal of Medical and Dental Sciences, vol. 3, no. 1, pp. 296-302, 2015.

[30] WHO, "Definition of an older or elderly person: Proposed Working Definition of an Older Person in Africa for the MDS Project," WHO Health statistics and health information systems, 2013, http://www.who.int/healthinfo/survey/ageingdefnolder/en/index.html.

[31] S. Sahin, P. T. Tasar, H. Simsek et al., "Prevalence of anemia and malnutrition and their association in elderly nursing home residents," Aging Clinical and Experimental Research, vol. 28, no. 5, pp. 857-862, 2016.

[32] V. Sgnaolin, P. Engroff, L. S. Ely et al., "Hematological parameters and prevalence of anemia among free-living elderly in south Brazil," Revista Brasileira de Hematologia e Hemoterapia, vol. 35, no. 2, pp. 115-118, 2013.

[33] A. Ramel, P. V. Jonsson, S. Bjornsson, and I. Thorsdottir, "Anemia, nutritional status, and inflammation in hospitalized elderly," Nutrition Journal, vol. 24, no. 11-12, pp. 1116-1122, 2008.

[34] A. Dunn, J. Carter, and H. Carter, "Anemia at the end of life: Prevalence, significance, and causes in patients receiving palliative care," Journal of Pain and Symptom Management, vol. 26, no. 6, pp. 1132-1139, 2003. 
[35] A. Contreras-Manzano, V. de la Cruz, S. Villalpando, R. Rebollar, and T. Shamah-Levy, "Anemia and iron deficiency in Mexican elderly population. Results from the Ensanut 2012," Salud Pública de México, vol. 57, no. 5, pp. 394-402, 2015.

[36] C. Beghé, A. Wilson, and W. B. Ershler, "Prevalence and outcomes of anemia in geriatrics: a systematic review of the literature," American Journal of Medicine, vol. 116, no. 7, supplement 1, pp. 3S-10S, 2004.

[37] L. Ferrucci, M. Maggio, S. Bandinelli et al., "Low testosterone levels and the risk of anemia in older men and women," JAMA Internal Medicine, vol. 166, no. 13, pp. 1380-1388, 2006.

[38] J. J. Carrero, P. Bárány, M. I. Yilmaz et al., "Testosterone deficiency is a cause of anaemia and reduced responsiveness to erythropoiesis-stimulating agents in men with chronic kidney disease," Nephrology Dialysis Transplantation, vol. 27, no. 2, pp. 709-715, 2012.

[39] V. W. Henderson, "Aging, estrogens, and episodic memory in women," Cognitive and Behavioral Neurology, vol. 22, no. 4, pp. 205-214, 2009.

[40] E. H. Haddad, L. S. Berk, J. D. Kettering, R. W. Hubbard, and W. R. Peters, "Dietary intake and biochemical, hematologic, and immune status of vegans compared with nonvegetarians," American Journal of Clinical Nutrition, vol. 70, no. 3, pp. 586s593s, 1999.

[41] J. Woo, T. Kwok, S. C. Ho, A. Sham, and E. Lau, "Nutritional status of elderly Chinese vegetarians," Age and Ageing, vol. 27, no. 4, pp. 455-461, 1998.

[42] R. Pawlak, S. E. Lester, and T. Babatunde, "The prevalence of cobalamin deficiency among vegetarians assessed by serum vitamin B12: A review of literature," European Journal of Clinical Nutrition, vol. 68, no. 5, pp. 541-548, 2014.

[43] R. Obeid, J. Geisel, H. Schorr, U. Hübner, and W. Herrmann, "The impact of vegetarianism on some haematological parameters," European Journal of Haematology, vol. 69, no. 5-6, pp. 275279, 2002.

[44] K. E. Charlton and D. Rose, "Nutrition among older adults in Africa: The situation at the beginning of the millenium," Journal of Nutrition, vol. 131, no. 9, pp. 2424S-2428S, 2001.

[45] I. Colombet, J. Pouchot, V. Kronz et al., "Agreement between erythrocyte sedimentation rate and C-reactive protein in hospital practice," American Journal of Medicine, vol. 123, no. 9, pp. 863.e7-863.e13, 2010.

[46] A. A. Merchant and C. N. Roy, "Not so benign haematology: Anaemia of the elderly," British Journal of Haematology, vol. 156, no. 2, pp. 173-185, 2012.

[47] C. N. Roy, "Anemia of Inflammation," International Journal of Hematology, vol. 2010, no. 1, pp. 276-280, 2011. 


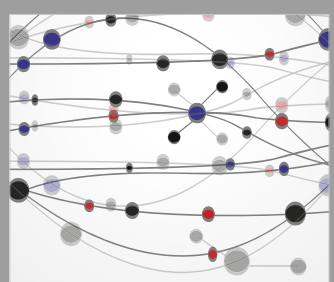

The Scientific World Journal
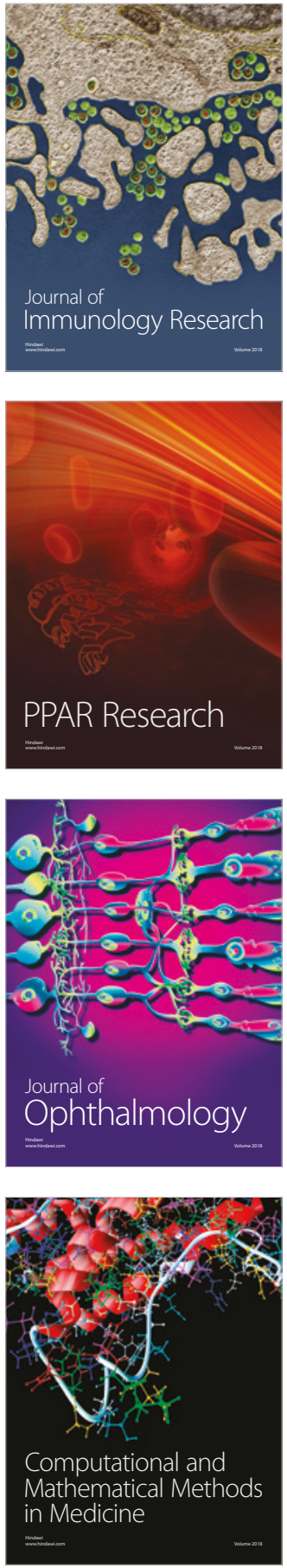

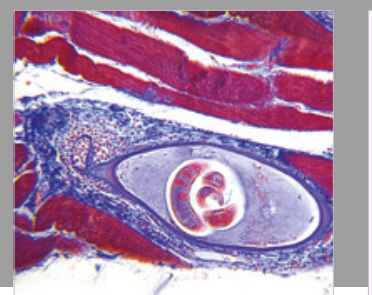

Gastroenterology Research and Practice

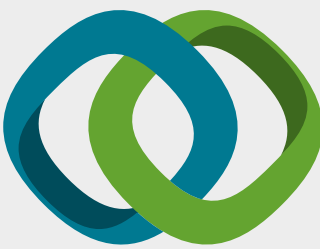

\section{Hindawi}

Submit your manuscripts at

www.hindawi.com
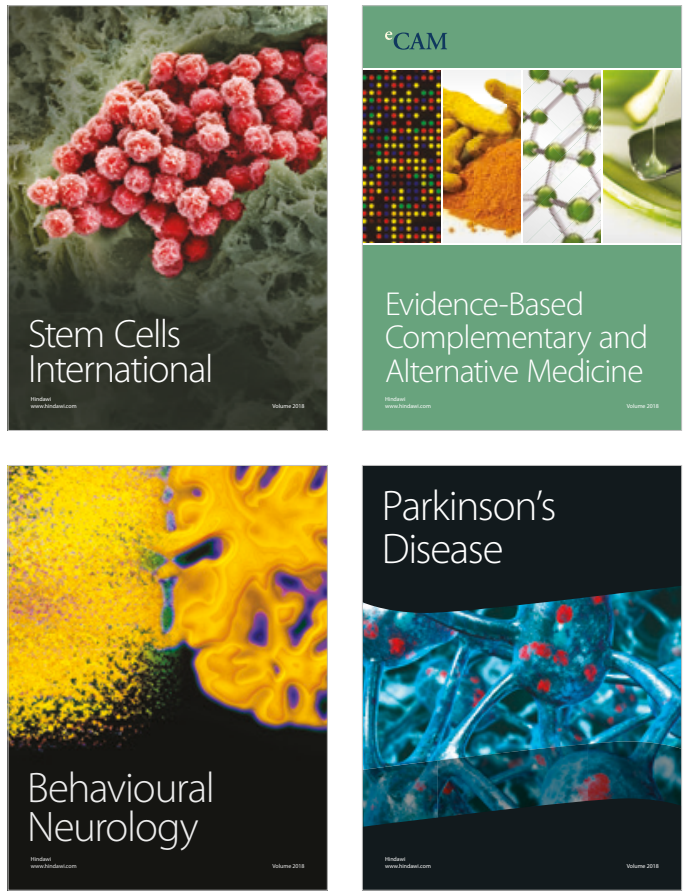

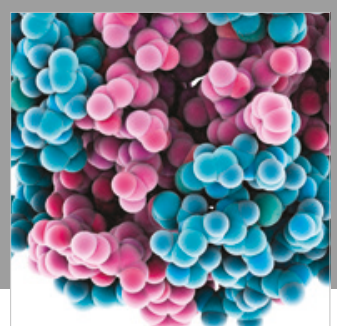

ournal of

Diabetes Research

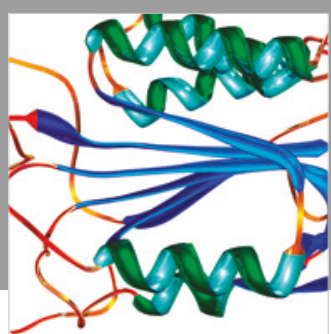

Disease Markers
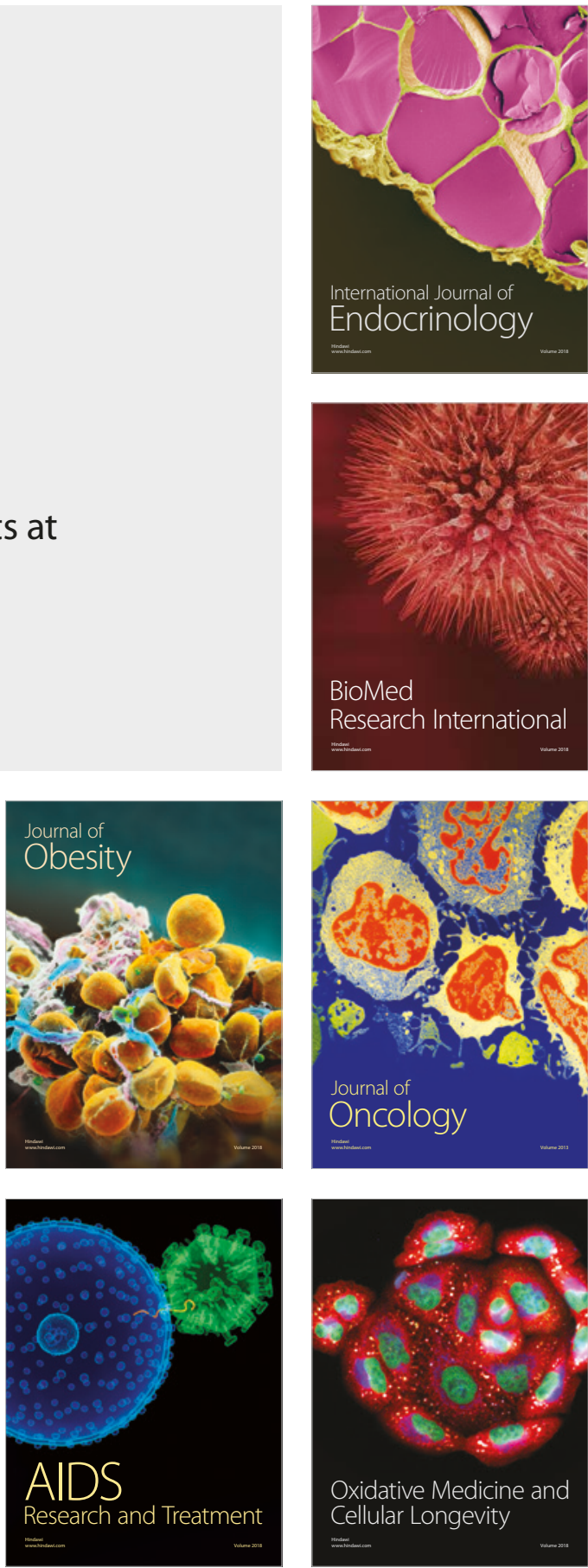